ISSN 2236-0859

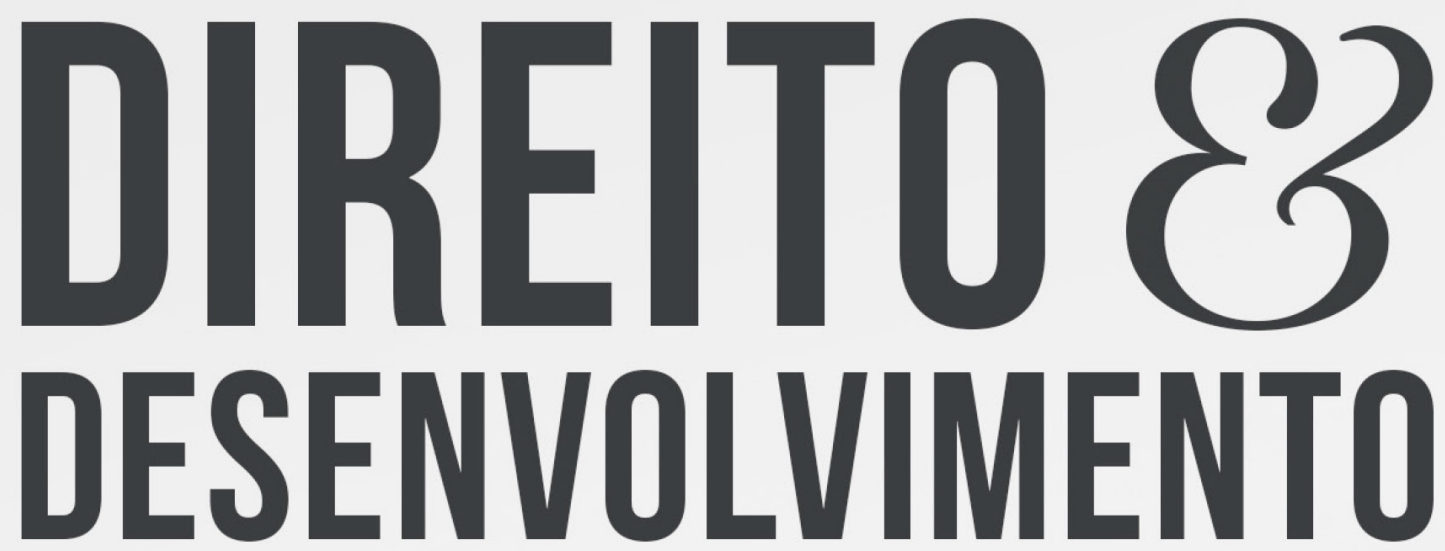

REVISTA DO PROGRAMA DE PÓS-GRADUAÇ̃̃O EM DIREITO MESTRADO EM DIREITO E DESENVOLVIMENTO SUSTENTÁVEL

\title{
DIREITO, DESENVOLVIMENTO E LIBERDADE: O DIREITO TRIBUTÁRIO PODE APRIMORAR ESSES CONCEITOS?
}

MARIA DE FÁTIMA RIBEIRO

LUCAS PIRES MACIEL 


\title{
DIREITO, DESENVOLVIMENTO E LIBERDADE: O DIREITO TRIBUTÁRIO PODE APRIMORAR ESSES CONCEITOS?
}

\author{
RIGHT, DEVELOPMENT AND FREEDOM: TAX LAW CAN \\ APPROPRIATE THESE CONCEPTS?
}

Recebido: 11/02/2020

Aprovado: 12/06/2020
Maria de Fátima Ribeiro ${ }^{1}$ Lucas Pires Maciel ${ }^{2}$

\section{RESUMO:}

O presente artigo tem como objetivo estudar o desenvolvimento e a liberdade como um binômio fundamental para o século XXI e o papel do Estado para o atingimento dessas políticas. Para isso, evidenciou-se que o Brasil vem criando programas que evidenciam uma melhoria no desenvolvimento e na liberdade dos cidadãos, seja de forma individual ou na coletividade. Ademais, diferenciou-se crescimento econômico e desenvolvimento econômico, aduzindo que não tem a mesma base de aferição, sendo que o Direito ao Desenvolvimento, previsto no texto constitucional, no artigo $3^{\mathbf{o}}$, como um dos objetivos da República Federativa do Brasil, requer mais que uma mera informação numérica, mas sim, uma efetiva mudança no índice de Desenvolvimento (IDH) da nação. A tributação, por isso, exerce papal fundamental, quando interfere na economia e faz política distributiva. Com isso, pode diminuir as desigualdades regionais, com a criação deáreas com tributação diferenciada, como por exemplo a Zona Franca de Manaus, que foi prorrogada até 2073, além de outras políticas como o Simples Nacional. Por isso, incrementar medidas político-fiscais é um mecanismo eficaz para que o Estado possa fomentar o atingimento do desenvolvimento atrelado a liberdade, com acréscimo nos resultados do Índice IRBES. Para elaboração do artigo utiliza-se o método dedutivo com pesquisas bibliográficas.

Palavras-chave: Crescimento. Desenvolvimento. Direito Tributário. Extrafiscalidade. Índice IRBES. Liberdade.

\begin{abstract}
:
This article aims to study development and freedom as a fundamental binomial for the 21st century and the role of the State in achieving these policies. For this, it was evidenced that Brazil has been creating programs that show an improvement in the development and freedom of citizens, either individually or collectively. In addition, economic growth and economic development were differentiated, arguing that it does not have the same basis of assessment,

\footnotetext{
1 Possui graduação em Direito pela Universidade Estadual de Londrina, Mestrado em Ciências Jurídicas Empresarias pela Pontifícia Universidade Católica do Rio de Janeiro, Doutorado em Direito pela Pontifícia Universidade Católica de São Paulo, Pós Doutorado em Direito Fiscal/Tributário na Universidade de Lisboa. Curso complementar créditos de Doutorado na Sapienza Università di Roma Facoltà di Economia e Facoltà di Giurisprudenza) Roma Itália. E-mail: professoramariadefatimaribeiro@gmail.com

2 Doutorando em Direito pela UNIMAR de Marília/SP, com término previsto para agosto de 2021, que tem como área de concentração: Empreendimentos econômicos, desenvolvimento e mudança social, na Linha de Pesquisa 1 ? Relações Empresariais, Desenvolvimento e Demandas Sociais. Mestre em Direito pela UNIMAR de Marília/SP, com término em março de 2018. É pós graduado em Direito do Estado - área de concentração Direito Tributário - pela Universidade Estadual de Londrina - UEL (2011), além de pós-graduado em Direito Tributário e Processo Tributário pelo Centro Universitário Antônio Eufrásio de Toledo de Presidente Prudente/SP (2009). Bacharel em Direito pelo Centro Universitário Antônio Eufrásio de Toledo de Presidente Prudente/SP. E-mail: lucas_jppm@hotmail.
} com.
\end{abstract}


and the Right to Development, provided for in the constitutional text, in article 3, as one of the objectives of the Federative Republic of Brazil, requires more than a mere numerical information, but an effective change in the Development Index (HDI) of the nation. Taxation, therefore, plays a fundamental role, when it interferes with the economy and makes distributive politics. With this, it can reduce regional inequalities, with the creation of areas with differentiated taxation, such as the Manaus Free Zone, which was extended until 2073, in addition to other policies such as Simples Nacional. Therefore, to increase political-fiscal measures is an effective mechanism for the State to promote the achievement of freedom-related development, with an increase in the results of the IRBES Index. For the elaboration of the article it is used the deductive method with bibliographical researches.

Keywords: Growth. Development. Tax law. Extrafiscality. IRBES Index. Freedom.

\section{INTRODUÇÃO}

O presente artigo tem como escopo estudar a liberdade e o desenvolvimento, por intermédio de ferramentas do Direito Tributário, conciliando os conceitos, para o fim de implementar os índices de desenvolvimento da sociedade e, com isso, melhorar o Índice de Desenvolvimento Humano brasileiro e melhor aplicar a carga tributária.

É cediço que o Brasil possui uma das mais altas carga tributárias do mundo e, uma das grandes críticas da grande população, é que parcela maior desses recursos arrecadados não chegam até as classes menos favorecidas e, por vezes, não se transforma em ferramentas de redistribuição de renda e/ou programas de diminuição de pobrezas ou desigualdades.

Casos de corrupção, como se vislumbra em várias operações da Polícia Federal, como exemplo, Operação “Lava Jato”, Operação “Zelotes”, Operação "Boca Livre”, entre outras espalhadas pelo Brasil, seja em âmbito federal, estadual ou municipal, deflagram o mal uso do dinheiro público e colocam em risco a liberdade e o desenvolvimento, deixando os contribuintes afastados do seu direito-dever de pagar tributos, haja vista escândalos de desvio de verbas fundamentais para o país.

Nessa senda, o Brasil vê-se diante de uma carga tributária crescentes nas últimas décadas, com aumento das obrigações sobre as pessoas físicas e jurídicas, com aumento na gama de direitos conferidos ao papel do Estado (lato sensu) e, ao mesmo tempo, um achatamento dos índices de pesquisa do desenvolvimento humano, na liberdade econômica, na expectativa de vida, na taxa de mortalidade infantil, nos índices de pobreza extrema, nas liberdades políticas e civis, entre outros critérios.

Essas bases indicativas colocam o Brasil como uma país com altas bases de tributação e baixa sensação de retorno em direitos individuais, sociais e coletivos, gerando uma sensação de que pagar tributo é um mero dever e não de que o tributo auxilia no desenvolvimento do país em vários aspectos.

Isso, pois, o desenvolvimento esperado pelos constituintes, quando da lavra da Constituição Federal, não se resumiria a um simples número no crescimento econômico e, nem ao menos, uma simples redistribuição de riquezas.

O que se almeja, em verdade, é a distribuição efetiva dessa riqueza em favor do bemestar social, gerando alterações significativas nos índices de desenvolvimento humano, com o fortalecimento da dignidade da pessoa humana, além da procura do fortalecimento das bases produtivas, obediente, por óbvio, ao meio ambiente sustentável, bem como, com a participação efetiva da sociedade nas decisões políticas nacionais, com o fito de alcançar um crescimento 
com mudanças significativas do Estado, com diminuição da pobreza, fome, fomento à educação, saúde, entre outros fatores.

Por isso, o uso consciente e correto da extrafiscalidade, pode gerar, em boa parcela, uma significativa melhora nos critérios da liberdade e do desenvolvimento do país, maximizando e potencializando o tão almejado desenvolvimento, com aprimoramento nos índices de desenvolvimento humano, afastando a sensação geral de que pagar tributo é jogar dinheiro fora.

A partir dessas ponderações, o artigo pretende elucidar quais ferramentas tributárias podem e/ou devem ser utilizadas pelo Estado, lato sensu, para ultrapassar as barreiras do mero crescimento econômico e, em outro patamar, alçar voos mais altos em busca do desenvolvimento.

Para elaboração do artigo foi utilizado o método dedutivo com pesquisas bibliográficas.

\section{DESENVOLVIMENTO E LIBERDADE: O BINÔMIO DO SÉCULO XXI}

Não é sem razão que o capítulo é intitulado como: "Desenvolvimento e liberdade: o binômio do século XXI", haja vista que é algo almejado e de difícil alcance, haja vista a existência de diversas barreiras que impedem o seu atingimento.

Ademais, é importante consignar que desenvolvimento e liberdade, além de serem objetivos, tem uma relação umbilical, haja vista que quanto maior o desenvolvimento maior a liberdade e vice-versa. Por óbvio, que essa regra possui exceções, porém, são raras. Isso, pois, como se demonstrará a seguir, no escopo desse capítulo, o Estado que é desenvolvido oferece maiores garantias individuais ao indivíduo e, sendo o indivíduo mais livre, aumenta-se as opções de um melhor desenvolvimento daquele Estado.

Alinhavou-se, alhures, que crescimento não é sinônimo de desenvolvimento. É cediço que crescer pressupõe a existência de aumento frio nos números de determinado País, o que, por si só, não repercute necessariamente em desenvolvimento. Desenvolver exige um dado mais abrangente, mais complexo e menos frio. Ordena que haja a presença de outros índices, que apontem, além do crescimento numérico e objetivo, a existência de mudança de patamares em direitos das pessoas que ali habitam.

Tanto é diferente crescimento e desenvolvimento, que a Constituição Federal acautelase em deixar claro, em algumas passagens, que o Estado deve alcançar e sempre buscar o desenvolvimento, ignorando, por óbvio, tratar de crescimento.

Veja-se que inicia o texto, no seu preâmbulo, aduzindo que a Assembleia Nacional Constituinte reuniu-se, com o objetivo de "instituir um Estado Democrático, destinado a assegurar o exercício dos direitos sociais e individuais, a liberdade, a segurança, o bem-estar, o desenvolvimento".

Outrossim, logo em seguida, no artigo $3^{\circ}$, da Constituição Federal, aduz que um dos objetivos fundamentais da República é o "garantir o desenvolvimento nacional". Interessante consignar que além dessas duas passagens indicadas, a Carta Magna anuncia a expressão "desenvolvimento" em outras 51 oportunidades, das mais variadas conotações e ambições, seja para o próprio Estado, seja para setores da iniciativa privada que o Constituinte almeja fomentar para melhoria nos números do país.

Amartya Sen (2000, p. 53) apresenta que o Desenvolvimento é "um processo de expansão das liberdades reais que as pessoas desfrutam". Prossegue asseverando que existem cinco liberdades que implementam o desenvolvimento: liberdades políticas, facilidades econômicas, oportunidades sociais, garantias de transparência e segurança protetora (SEN, 2000, p. 55). 
A liberdade política seriam as oportunidades que as pessoas teriam para determinar quem deve governar e quais instrumentos possui de fiscalizar e criticar as autoridades, além das liberdades de expressão política e da imprensa. Facilidades econômicas as oportunidades se relacionam com a questão do desenvolvimento econômico aumentando a riqueza e a renda de um país e o subsequente aumento dos bens da população. Oportunidades sociais dizem respeito aos direitos de educação, saúde, e outros direitos sociais que interferem na vida do cidadão, como exemplo do analfabetismo e/ou morte de recém-nascidos por ausência de saúde básica de qualidade. Realiza liame entre esse direito e a liberdade política, uma vez que, sem educação, como exercer a liberdade política? A garantia de transparência tem um aspecto já mencionado na introdução, ao passo que é exatamente a existência de garantias inibidoras da corrupção, das irresponsabilidades financeiras, transações ilícitas, políticas que firam a lei de responsabilidade fiscal. Por último, a necessidade da existência de uma teia de segurança nacional, que coloca em rede os sistemas de proteção aos vulneráveis. Isso incluiriam os desempregados, suplementos de renda aos indigentes, como distribuição excepcional de alimentos em caso de grave crise para os necessitados (SEN, 2000, p. 55-57).

O autor Ignacy Sachs, por sua vez, elabora crítica aos conceitos tradicionais de Desenvolvimento, uma vez que assevera que tem funcionado como "uma armadilha ideológica construída para perpetuar as relações assimétricas entre as minorias dominadoras e as maiorias dominadas, dentro de cada país e entre os países" (SACHS, 2008, p. 26).

Por isso, sugere uma aproximação entre a ética, a economia e a política, dando um novo viés para o Desenvolvimento. Sugere um desenvolvimento global, mas assevera que é uma situação remota (SACHS, 2008, p. 27). Veja a sua constatação:

\footnotetext{
Mesmo hoje, as economias em desenvolvimento ainda podem ser descritas como arquipélagos de empresas modernas com alta produtividade do trabalho, imersas no oceano de atividades de produtividade baixa ou muito baixa, que formam o tecido intersticial do sistema econômico. A maior parte do PIB vem do arquipélago. A maior parte das pessoas nadam no oceano, tentando sobreviver. (SACHS, 2008, p. 31)
}

Segundo Ignacy Sachs (2008, p. 13) desenvolvimento é algo diametralmente oposto ao que se chama de crescimento. Como já mencionado, o crescimento leva em consideração apenas os números de maneira fria, ou seja, se houve aumento numérico, pura e simplesmente. O desenvolvimento, em complemento, remonta-se em informações mais pormenorizadas, em consideração a aspectos mais humanos. O autor obtempera que o desenvolvimento vai além "da mera multiplicação da riqueza material" (SACHS, 2008, p. 13), ou seja, da consideração impessoal dos números da economia.

É evidente que o crescimento é um dado importante no aparato de um Estado, sendo uma "condição necessária", porém, o que adverte é que o crescimento não é uma informação suficiente, nem ao menos um "objetivo em si mesmo", para alcançar uma "vida melhor, mais feliz e mais completa para todos" (SACHS, 2008, p. 13).

Sachs prossegue aduzindo que o Desenvolvimento deve assegurar aos cidadãos as três gerações de direito humanos, quais sejam, políticos, civis e cívicos; econômicos, sociais e culturais (trabalho digno); coletivos ao meio ambiente (SACHS, 2008, p. 14).

Por isso, em complemento às lições de Sachs, A martya Sen, na sua obra "Desenvolvimento como liberdade" assinala que "o desenvolvimento pode ser visto como um processo de expansão das liberdades reais que as pessoas desfrutam" (SEN, 2000, p. 17).

Contudo, o autor Ignacy Sachs realiza crítica aos conceitos tradicionais de Desenvolvimento, uma vez que tem funcionado como "uma armadilha ideológica construída 
para perpetuar as relações assimétricas entre as minorias dominadoras e as maiorias dominadas, dentro de cada país e entre os países" (SEN, 2000, p. 26).

Nesse contexto, a Constituição Federal de 1988 coloca com grande destaque o desenvolvimento, haja vista que já no preâmbulo do texto constitucional enuncia que o Estado brasileiro se institui a partir desta Carta e está compromissado, dentre outros fins, a assegurar o desenvolvimento da sociedade brasileira.

Avança o texto constitucional ao atribuir no seu artigo $3^{\circ}$ que é um dos objetivos da República a garantia do desenvolvimento nacional. Há outras passagens importantes e impactantes acerca da temática no texto constitucional.

Com essa base, importante ressaltar que Sachs (2008, p. 14-15) entende que "em vez de maximizar o crescimento do PIB, o objetivo maior se torna promover a igualdade e maximizar a vantagem daqueles que vivem nas piores condições, de forma a reduzir a pobreza”.

Para Thomas Piketty (2014, p. 114) "desenvolvimento representa uma grande parte da melhoria das condições de vida".

Celso Furtado (1984, p. 63) obtempera que o desenvolvimento é um processo de transformação do mundo realizado pelo homem com o intento de atender às suas necessidades. Porém, não deve ficar adstrito a isso, pois para que consigam atender essas necessidades, mister se faz elevar os potenciais de invenção cultural, conseguindo assim as transformações esperadas. E é justamente em razão da evolução desse processo de invenção cultural que ocorre o aprimoramento e exaltação da tecnologia em seu alto poder de difusão.

O mesmo autor assim se posiciona sobre o desenvolvimento:

Avisão que tenho do desenvolvimento éa de um processo criativo, de invenção da História pelos homens, em contraste com o quadro mimético e repetitivo de que são prisioneiras as sociedades dependentes. Em nossa civilização, o processo de desenvolvimento se faz com crescente ampliação da base material da cultura e também com enriquecimento do horizonte de expectativas do ser humano. Desenvolver-se é ascender na escala de realização das potencialidades dos homens como indivíduos e como coletividade (FURTADO, 1984, p. 63).

Analisado o aspecto do Desenvolvimento, importante qualificar, ainda que rapidamente, aspectos sobre a liberdade, que é um direito conquistado à duras penas pelas gerações passadas e que, ainda, é tão caro para muitos Estados e inexistente em tantos outros. Amartya Sen (2000, p. 331) analisa o conceito de liberdade e realiza a distinção entre o aspecto da oportunidade da liberdade e o aspecto do processo de liberdade. Para ele a liberdade tem, por fim, papel construtivo na formação de valores e éticas.

Para Amartya Sem (2000, p. 325) liberdade é a oportunidade de fazer escolhas. Se não pode fazer escolhas, logo, não tem liberdade. Capacidade atrelada à liberdade e escolhas.

Realizando a intersecção conceitual entre desenvolvimento e liberdade, Peter Bauer possui salutar consideração acerca, ao consignar que havendo aumento da diversidade de alternativas concretas disponíveis para as pessoas, o principal objetivo e critério do desenvolvimento é atingido ${ }^{3}$.

Amartya Sem (2000, p. 330) é bastante enfático em aduzir que não é porque existe aumento da produção ou renda ou de geração de consumo elevado que haverá melhoria no processo de tomada de decisão e oportunidades de escolhas. Por isso, não se pode imediatamente concluir que se a pessoa tem condição econômica privilegiada que terá liberdade, pois ter condições financeiras lhe dá oportunidade de adquirir os bens que quiser, mas isso não quer dizer que esses dados sejam positivos também para liberdade, ou seja, "para viver uma vida 
longa ou o potencial para escapar da morbidez evitável, a oportunidade de ter um emprego que valha a pena ou de viver em comunidades pacíficas e isentas de criminalidade" (SEN, 200o, p. 330).

Assim, Amartya Sen (2000, p. 330) obtempera que há que se afastar de conceitos convencionais de desenvolvimento e relacioná-los com a liberdade, não importando, somente, "crescimento do produto per capita".

Nesse viés, Amartya Sen (200o, p. 22) assevera que o "desafio da sociedade é formular políticas que permitam, além do crescimento da economia, a distribuição mais equitativa da renda e o pleno funcionamento da democracia". Por isso, desenvolver não é somente crescer.

Por isso, o Desenvolvimento deve ser meio de se atingir o aprimoramento dos índices de vida das pessoas e para ampliar essas capacidades de escolha, haja vista que a liberdade não é meio para o desenvolvimento, pois ela é o meio e o fim do desenvolvimento. É algo muito maior e mais complexo.

Assim, do que foi exposto, mister fechar esse tópico aduzindo que "desenvolvimento é realmente um compromisso muito sério com as possibilidades de liberdade" (SEN, 200o, p. 337), haja vista que almejar o desenvolvimento perpassa, sem dúvida, por uma oportunidade de participação nos aspectos sociais do Estado, com o fito de construir uma sociedade com valores e ética. Para Sen, "o que as pessoas conseguem realizar é influenciado por oportunidades econômicas, liberdades políticas, poderes sociais e por condições habilitadoras, como boa saúde, educação básica e incentivo e aperfeiçoamento de iniciativas" (SEN, 200o, pág. 18).

\section{REALIDADE DO BRASIL: AUMENTAR AS LIBERDADES PARA MELHORAR O DESENVOLVIMENTO?}

A despeito de problemas sociais, legais, estruturais, organizacionais e de outras searas, o Brasil é um país que tem contornos de liberdade, nas mais variadas conotações, a despeito de ter problemas de ordem desenvolvimentista.

Todavia, ainda que existente essas premissas, há uma série de barreiras burocráticas que atrapalham o alcance de um melhor critério de desenvolvimento, o que de certa forma tolhe a tão desejada liberdade. O Brasil é conhecido por ser uma Estado interventor em diversos assuntos de índole econômica. É evidente que não é uma crítica pura e simples, pois, em vários aspectos é necessária a intervenção estatal, especialmente em assuntos que envolvam vulneráveis e hipossuficientes.

Por seu turno, há alguns aspectos jurídicos-legais que poderiam ser flexibilizados pelo Estado, sob o bojo de implementar uma maior procura dos empresários e agentes econômicos, afastando-os do emaranhado de normas das mais variadas estirpes.

Isso, sem dúvida, serve como um sistema de frenagem ao desenvolvimento, haja vista que os investidores preferem não investir, com receio de que burocracias e exigências administrativas emperrem ou onerem o negócio.

Nesse jaez, o Estado se torna inimigo de si mesmo, haja vista que ao minimizar as liberdades dos indivíduos, seja nas pessoas físicas ou jurídicas, retrai o desenvolvimento econômico, aumentando os índices de desemprego, violência, inadimplência, minorando a credibilidade no país para os investidores internacionais. Em poucas palavras, as medidas estatais criam óbices para o crescimento e desenvolvimento do país, camuflado em regras, normas, instruções, regulamentos, portarias e tantas outras bases jurídicas.

Assim, o medo de empreender é maior do que a vontade de alavancar o dinheiro e, com isso, a liberdade torna-se uma barreira quase intransponível ao desenvolvimento da nação. 
Um outro obstáculo bastante duro ao investimento é a questão tributária. É notório que o Brasil possui um sistema tributário bastante complexo e pesado para o investidor, chegando ao absurdo de Alfredo Augusto Becker chamar o sistema tributário brasileiro de "manicômio jurídico-tributário" ou "carnaval tributário", fazendo alusão às questões tributárias que tanto atormentam os aplicadores.

Com base nessa perspectiva, alguns institutos passaram a desenvolver estudos acerca da carga tributária, seus números, dados de arrecadação, índices de sonegação, entre outros. Um deles, bastante interessante é o desenvolvido pelo Instituto Brasileiro de Planejamento e Tributação, além de outros como impostômetro, que é o Cálculo do IRBES (Î́ndice de Retorno de Bem-Estar à Sociedade) - Estudo Sobre a Carga Tributária/PIB x IDH - maio de 2015².

Nessa pesquisa foi utilizado o Índice de Desenvolvimento Humano (IDH) do ano de 2013 e fez-se o inventário dessas informações em trinta países e, como exposto na própria pesquisa, o IDH é uma "medida comparativa de riqueza, alfabetização, educação, esperança de vida, natalidade e outros fatores para os diversos países do mundo. É uma maneira padronizada de avaliação e medida do bem-estar de uma população, especialmente bem-estar infantil”.

A metodologia de pesquisa desse índice leva em consideração a "somatória do valor numérico relativo à carga tributária do país, com uma ponderação de 15\%, com o valor do IDH, que recebeu uma ponderação de $85 \%$ "

Para isso o IRBES leva em consideração a base do IDH e a carga tributária do país, fazendo uma relação entre o índice de desenvolvimento humano com aquilo que as pessoas pagam aos cofres públicos à título de tributos, ponderando se pagar mais tributo significa necessariamente ter um melhor desenvolvimento.

Os dados são interessantes e, dos trinta países avaliados, nota-se que os seis primeiros colocados (Austrália, Coreia do Sul, Estados Unidos da América, Suíça, Irlanda e Japão) tem uma carga tributária inferior a 30\% e tem os melhores IDHs, o que reflete nas melhores colocações no IRBES, enquanto que os últimos colocados, à exceção do Brasil, tem carga tributária maior que $40 \%$ e não tem um bom IDH, figurando como os últimos da lista.

A posição do Brasil é a mais interessante, pois tem uma carga tributária média pelo padrão dos países avaliados, contudo, tem um IDH baixo, o que o coloca na última posição do IRBES, haja vista a falta de retorno entre a carga tributária exigida os critérios do IDH.

Isso, reforça o que foi exposto no capítulo acima, ao fato de que a liberdade no Brasil se torna minorada pela carga tributária alta e pelos baixos índices de retorno desses tributos, o que denota que o desenvolvimento é prejudicado deveras. Ralos da corrupção, desvios, burocracia, problemas estruturais, uma país de dimensões continentais vão colocando o Brasil em posição desfavorecida quando o assunto é liberdade econômica e desenvolvimento efetivo.

Por isso, dos zo países avaliados o Brasil é o último colocado, abaixo de países como Israel, Argentina, Grécia, Uruguai e Luxemburgo. O uso de medidas que prestigiem a flexibilização das burocracias e carimbos em órgãos fiscais tendem a melhorar esses números.

O estudo indicou, portanto, que, entre os 30 países com a maior carga tributária, o Brasil é o que proporciona o pior retorno dos valores arrecadados em prol do bem-estar da sociedade. O Brasil, com arrecadação altíssima e péssimo retorno desses valores, fica atrás, inclusive, de países da América do Sul, como Uruguai e Argentina.

Entretanto, algumas medidas foram e estão sendo tomadas para o fim de amenizar as amarras jurídico-legais que tanto atravancam o país, criando uma maior flexibilidade em temáticas até então encampadas fortemente pelo Estado e que, agora, passaram a permitir um abrandamento estatal.

4 AMARAL, Gilberto do Amaral; OLENIKE, João Eloi; AMARAL, Letícia Mary Fernandes do. Cálculo do IRBES. Disponível em: <http://ibpt.impostometro.s3.amazonaws.com/Arquivos/o6\%2BIRBES\%2B2015.pdf>. Acesso em: 10 jun. 2019. 
Uma primeira que pode ser citada é a figura do Microempreendedor Individual (MEI), instituída pela Lei Complementar no 128 , de 19 de dezembro de 2008 , que alterou a Lei Complementar no 123 , de 14 de dezembro de $2006^{8}$, mais conhecida com a Lei do Simples Nacional, que instituiu o Estatuto Nacional da Microempresa e da Empresa de Pequeno Porte. É uma forma mais simplificada de inserir na formalidade profissionais que até então, na sua grande maioria, laboravam à margem da legislação tributária e trabalhista, desembocando em problemas variados e, que foi amenizado, por essa legislação. Vale consignar que recentemente a figura do MEI passou por novas mudanças, aumentando o faturamento máximo anual, por meio da Lei Complementar no ${ }^{155}$, de 27 de outubro de $2016^{9}$.

É um regime muito interessante e minora obrigações acessórias, burocracias, inclui as pessoas que até então eram informais e lhes garantem acesso a direitos sociais, tal como, aposentadorias, auxílios e licenças do INSS. O Portal do Empreendedor divulgou que tem-se, até o dia 22 de junho de 2019, 8.518.888 de microempreendedores individuais ${ }^{10}$. São milhões de pessoas que saíram da marginalidade legal para regularizar e melhorar os índices de desenvolvimento.

Essa mesma lei complementar citada, criou recentemente a figura do investidoranjo, qual seja pela Lei Complementar no 155, de 27 de outubro de 2016, que servirá como um fomentador das micro, pequenas e empresas de pequeno porte nacionais, uma vez que o Simples é expresso em mencionar que somente se valerá do regime empresas que sejam eminentemente nacionais. Assim, o investidor-anjo, segundo a lei "não será considerado sócio nem terá qualquer direito a gerência ou voto na administração da empresa", "não responderá por qualquer dívida da empresa, inclusive em recuperação judicial, não se aplicando a ele o art. 50 da Lei no 10.406, de 10 de janeiro de 2002 - Código Civil" e, "será remunerado por seus aportes, nos termos do contrato de participação, pelo prazo máximo de cinco anos"1.

Cabe mencionar que a própria criação da Lei Complementar no 123/2006 é uma boa iniciativa para minorar as burocracias e obstáculos para os empreendedores. Contudo, o regime tributário do Simples, em muitas de suas faces, só tem de simples o nome, pois passa por diversas mudanças e se torna cada vez mais complexo na sua utilização. Ainda assim, é mais simplificado que os demais regimes fiscais das empresas.

Outra medida interessante e que tem o condão de implementar o desenvolvimento e minorar problemas com acesso ao crédito e fomento à novos negócios é a Lei Complementar no $166^{12}$, de o8 de abril de 2019, que dispõe sobre os cadastros positivos de crédito e regular a responsabilidade civil dos operadores. Segundo o Ministério da Economia essa legislação

7 BRASIL. LEI COMPLEMENTAR № 128, DE 19 DE DEZEMBRO DE 20o8. Altera a Lei Complementar no 123, de 14 de dezembro de 2006, altera as Leis nos 8.212, de 24 de julho de 1991, 8.213, de 24 de julho de 1991, 10.406, de 10 de janeiro de 2002 - Código Civil, 8.029, de 12 de abril de 1990, e dá outras providências. Disponível em: <http://www.planalto.gov.br/ccivil_03/leis/lcp/lcp128.htm>. Acesso em: 23 jun. 2019.

8 BRASIL. LEI COMPLEMENTAR № 123, DE 14 DE DEZEMBRO DE 20o6. Institui o Estatuto Nacional da Microempresa e da Empresa de Pequeno Porte; altera dispositivos das Leis no 8.212 e 8.213, ambas de 24 de julho de 1991, da Consolidação das Leis do Trabalho - CLT, aprovada pelo Decreto-Lei no 5.452, de 10 de maio de 1943, da Lei no 10.189, de 14 de fevereiro de 2001, da Lei Complementar no 63, de 11 de janeiro de 1990; e revoga as Leis no 9.317, de 5 de dezembro de 1996, e 9.841, de 5 de outubro de 1999. Disponível em: <http://www.planalto.gov.br/ccivil_03/leis/lcp/lcp128.htm>. Acesso em: 23 jun. 2019.

9 BRASIL. LEI COMPLEMENTAR № 155, DE 27 DE OUTUBRO DE 2016. Altera a Lei Complementar no 123, de 14 de dezembro de 2006, para reorganizar e simplificar a metodologia de apuração do imposto devido por optantes pelo Simples Nacional; altera as Leis nos 9.613, de 3 de março de 1998, 12.512, de 14 de outubro de 2011, e 7.998, de 11 de janeiro de 1990; e revoga dispositivo da Lei no 8.212, de 24 de julho de 1991. Disponível em: <http://www.planalto.gov.br/ccivil_03/leis/lcp/lcp128.htm>. Acesso em: 23 jun. 2019. 1o BRASIL. Portal do Empreendedor. Disponível em: <http://www.portaldoempreendedor.gov.br/estatisticas >. Acesso em: 23 jun. 2019.

11 BRASIL. LEI COMPLEMENTAR № 155, DE 27 DE OUTUBRO DE 2016. Altera a Lei Complementar no 123, de 14 de dezembro de 2006, para reorganizar e simplificar a metodologia de apuração do imposto devido por optantes pelo Simples Nacional; altera as Leis nos 9.613, de 3 de março de 1998, 12.512, de 14 de outubro de 2011, e 7.998, de 11 de janeiro de 1990; e revoga dispositivo da Lei no 8.212, de 24 de julho de 1991. Disponível em: <http://www.planalto.gov.br/ccivil_03/leis/lcp/lcp128.htm>. Acesso em: 23 jun. 2019. 12 BRASIL. LEI COMPLEMENTAR № 166, DE o8 DE ABRIL DE 2019. Altera a Lei Complementar oㅜ 105, de 10 de janeiro de 2001 , e a Lei no 12.414 , de 9 de junho de 2011, para dispor sobre os cadastros positivos de crédito e regular a responsabilidade civil dos operadores. Disponível em: <http://www.planalto.gov.br/ccivil_03/leis/lcp/Lcp166.htm>. Acesso em: 21 jun. 2019. 
objetiva que todas as instituições tenham acesso às mesmas informações de cada consumidor ou empreendedor, possibilitando, portanto, um aumento da competição com o oferecimento de empréstimo mais personalizados aos diferentes perfis de capacidade de pagamento. Com base em perspectivas otimistas expecta-se que com o Cadastro ocorra a injeção de um trilhão de reais na economia, com impacto de aproximadamente $19 \%$ na relação crédito/PIB, ou seja, de $47 \%$ para $66 \%{ }^{13}$.

A Lei Complementar no ${ }^{\mathbf{1 6}} \mathbf{7} / \mathbf{2 0 1 9} \mathbf{9}^{14}$, de 24 de abril de 2019, instituiu a Empresa Simples de Crédito (ESC), de âmbito municipal ou distrital, com atuação exclusivamente no Município de sua sede e em Municípios limítrofes, ou, quando for o caso, no Distrito Federal e em Municípios limítrofes, destina-se à realização de operações de empréstimo, de financiamento e de desconto de títulos de crédito, somente com recursos próprios, tendo como contrapartes microempreendedores individuais, microempresas e empresas de pequeno porte, com o fito claro de tentar melhorar a liberdade para acesso a crédito e aprimorar o desenvolvimento.

A mesma e novel lei criou, também, o Inova Simples, regime especial simplificado que concede às iniciativas empresariais de caráter incremental ou disruptivo que se autodeclarem como startups ou empresas de inovação tratamento diferenciado com vistas a estimular sua criação, formalização, desenvolvimento e consolidação como agentes indutores de avanços tecnológicos e da geração de emprego e renda, objetivando melhorar a liberdade para iniciar um novo negócio e aprimorar o desenvolvimento.

A Medida Provisória no 881 , de 30 de abril de $2019^{15}$, instituiu a Declaração de Direitos de Liberdade Econômica, estabelece garantias de livre mercado, análise de impacto regulatório, e dá outras providências, com o intuito claro de tentar criar um Estado menos interventor para fomentar o desenvolvimento.

Outra legislação atual e bastante interessante diz respeito ao denominado Programa Rota 2030 - Mobilidade e Logística, fruto da Lei ํo 13.755/2018 ${ }^{16}$, corolário da Medida Provisória no $843^{17}$, de 05 de julho de 2018, que segundo o Ministério da Economia tem como escopo ampliar a inserção global da indústria automotiva brasileira, por meio da exportação de veículos e autopeças, gerando progressivamente um movimento de inserção global, para que o país esteja inteiramente inserido e no estado das artes da produção global de veículos automotores ${ }^{18}$.

Esse Programa é bastante interessante e atua em vários setores do Estado. Assim, as políticas traçadas por esse Programa tem o escopo de estimular a pesquisa e o desenvolvimento, além de lhes conferir condições de competitividade para que tais atividades possam ocorrer no País ${ }^{19}$.

13 BRASIL. Ministério da Economia. Medida que facilitará acesso ao crédito foi sancionada nesta segunda-feira (8). Disponível em: <http://www.economia.gov.br/noticias/2019/04/medida-que-facilitara-acesso-ao-credito-e-sancionada-nesta-segunda-feira-o8>. Acesso em: 21 jun. 2019.

14 BRASIL. LEI COMPLEMENTAR № 167, DE 24 DE ABRIL DE 2019. Dispõe sobre a Empresa Simples de Crédito (ESC) e altera a Lei no 9.613, de 3 de março de 1998 (Lei de Lavagem de Dinheiro), a Lei no 9.249, de 26 de dezembro de 1995, e a Lei Complementar no 123, de 14 de dezembro de 2006 (Lei do Simples Nacional), para regulamentar a ESC e instituir o Inova Simples. Disponível em: <http://www.planalto.gov.br/ccivil_03/leis/lcp/Lcp167.htm>. Acesso em: 21 jun. 2019.

15 BRASIL. MEDIDA PROVISÓRIA № 881, DE 30 DE ABRIL DE 2019. Institui a Declaração de Direitos de Liberdade Econômica, estabelece garantias de livre mercado, análise de impacto regulatório, e dá outras providências. Disponível em: <http://www. planalto.gov.br/ccivil_03/_ato2019-2022/2019/Mpv/mpv881.htm>. Acesso em: 21 jun. 2019.

16 BRASIL. LEI № 13.755, DE 1o DE DEZEMBRO DE 2018. Estabelece requisitos obrigatórios para a comercialização de veículos no Brasil; institui o Programa Rota 2030 - Mobilidade e Logística; dispõe sobre o regime tributário de autopeças não produzidas; e altera as Leis $\mathrm{n} \cong 9.440$, de 14 de março de 1997, 12.546, de 14 de dezembro de 2011, 10.865, de 30 de abril de 2004, 9.826, de 23 de agosto de 1999, 10.637, de 30 de dezembro de 2002, 8.383, de 30 de dezembro de 1991, e 8.989, de 24 de fevereiro de 1995, e o Decreto-Lei no 288, de 28 de fevereiro de 1967. Disponível em: <http://www.planalto.gov.br/ccivil_03/_ato2015-2018/2018/Lei/L13755.htm>. Acesso em: 21 jun. 2019.

17 BRASIL. MEDIDA PROVISÓRIA № 843, DE 5 DE JULHO DE 2018. Estabelece requisitos obrigatórios para a comercialização de veículos no Brasil, institui o Programa Rota 2030 - Mobilidade e Logística e dispõe sobre o regime tributário de autopeças não produzidas. Disponível em: <http://www.planalto.gov.br/ccivil_03/_ato2015-2018/2018/Mpv/mpv843.htm>. Acesso em: 21 jun. 2019. 18 BRASIL. MINISTÉRIO DA ECONOMIA. Rota 2030 - Mobilidade e Logística. Disponível em: <http://www.mdic.gov.br/index. $\mathrm{php} /$ competitividade-industrial/setor-automotivo/rotaz030>. Acesso em: 21 jun. 2019. 19 Idem. 
Veja-se que são medidas atuais e que almejam uma diminuição nas amarras burocráticas e tendem a incrementar o desenvolvimento. É cediço que ainda há muito a ser feito, haja vista que ainda tem-se no Brasil regras bastante impositivas e que limitam a liberdade de empreender, mas que, com o tempo, estão sendo mais flexibilizadas em prol de um desenvolvimento nacional mais completo.

Tanto é verdade que em 2018 foi divulgada pesquisa demonstrando que o Brasil ocupa a $64^{\text {a }}$ posição entre as economias mais inovadoras, segundo o Global Innovation Index $(\mathrm{GII})^{20}$. O Brasil sendo a maior economia da América Latina e Caribe subiu cinco posições em relação ao estudo de 2017 , mas segue no meio da tabela dos países analisados. O estudo é publicado anualmente pela Universidade Cornell, situada em Nova Iorque, nos Estados Unidos da América, pelo Insead e pela Organização Mundial da Propriedade Intelectual (OMPI) ${ }^{21}$. O Brasil não é o líder do ranking na américa latina, posição essa ocupada pelo vizinho Chile ${ }^{22}$.

O país vizinho se destaca pela "qualidade regulatória, matrículas no ensino superior, acesso a crédito, empresas que oferecem treinamento formal, abertura de novas empresas e fluxos de entrada e de saída de investimentos externos diretos" ${ }^{23}$.

O Brasil, por sua vez, tem "força comparativa nos gastos com pesquisa e desenvolvimento, importações e exportações de alta tecnologia, qualidade de publicações científicas e de universidades" ${ }^{24}$.

Segundo dados de 2013 o Brasil investe $1,3 \%$ do seu PIB em desenvolvimento, o que coloca o país em 36으 colocado na lista feita ONG Batelle ${ }^{25}$.

Assim, diante do que foi exposto medidas que tendam a melhorar os padrões de liberdade para o exercício de atividades econômicas são ferramentas valiosas ao aprimoramento dos índices de desenvolvimento nacional, haja vista que geram um círculo positivo de criação de números positivos, implementando renda, emprego, e, com isso, implementação dos índices de desenvolvimento humano.

Assim, o foco desse capítulo foi fazer o liame entre o capítulo inaugural e abrir as discussões acerca do que se tratará no capítulo seguinte, quando discorrerá acerca da importância das ferramentas tributárias para aprofundar essas políticas governamentais de aquilatar o tão desejado desenvolvimento com respeito às liberdades.

\section{FERRAMENTAS TRIBUTÁRIAS PARA FOMENTAR O DESENVOLVIMENTO COM LIBERDADE}

Importante salientar que o tributo possuir caráter de neutralidade, ou seja, não devendo ser fomentador de gerar quebra no equilíbrio natural do mercado, ocasião em que os tributos não deverão interferir diretamente na formação dos preços dos produtos e serviços, sob pena de vilipendiar a livre iniciativa e a livre concorrência, gerando danos ao desenvolvimento.

\footnotetext{
20 Índice Global de Inovação.

21 GLOBAL INNOVATION INDEX. Disponível em: <https://www.globalinnovationindex.org/Home>. Acesso em: 21 jun. 2019. 22 CORREIO BRAZILIENSE. China está entre as 20 economias mais inovadoras; Brasil ocupa $64^{\circ}$ lugar. Disponível em: <https:// www.correiobraziliense.com.br/app/noticia/economia/2018/o7/10/internas_economia,694018/china-esta-entre-as-20-economiasmais-inovadoras-brasil-ocupa-64-lug.shtml>. Acesso em 21 jun. 2019.

23 CORREIO BRAZILIENSE. China está entre as 20 economias mais inovadoras; Brasil ocupa 64º lugar. Disponível em: <https:// www.correiobraziliense.com.br/app/noticia/economia/2018/o7/10/internas_economia,694018/china-esta-entre-as-20-economiasmais-inovadoras-brasil-ocupa-64-lug.shtml>. Acesso em 21 jun. 2019.

24 NAÇÕES UNIDAS BRASIL. China entra para grupo de 20 economias mais inovadoras do mundo. Disponível em: <https:// nacoesunidas.org/china-entra-para-grupo-de-20-economias-mais-inovadoras-do-mundo/>. Acesso em: 21 jun. 2019. 25 CALEIRO, João Pedro. 15 países que mais investem em pesquisa (e o Brasil em 36o). Disponível em: <https://exame.abril. com.br/economia/15-paises-que-mais-investem-em-pesquisa-e-o-brasil-em-36o/>. Acesso em: 21 jun. 2019.
} 
Entretanto, o Estado, em momentos imperativos, deve utilizar do tributo como forma de intervir na economia, mesmo que quebrando a liberdade do mercado, como forma de evitar desequilíbrios mais nefastos.

Tem-se a noção correta de que o tributo tem papel primordial de arrecadação de recursos para a manutenção das funções precípuas do Estado, ante sua perspectiva arrecadatória, almejando financiar o sistema público de garantias dos cidadãos, ou seja, o funcionamento do próprio Estado de Direito, conforme Holmes e Sunstein apud Suzana Tavares da Silva (2015, p. 23).

Ocorre que, a despeito de ser de suma importância essa função, o tributo não pode se satisfazer somente nesse degrau, devendo evoluir para uma outra função, cunhada no escopo de diminuir as desigualdades sociais, regionais, por meio da produção de bens e serviços públicos e de acesso universal financiado pelos tributos, como por exemplo saúde e educação, como explicita Suzana Tavares da Silva (2015, p. 23).

Em Portugal a Lei Geral Tributária, no seu artigo $5^{\circ}$ aduz que "a tributação visa a satisfação das necessidades financeiras do Estado e de outras entidades públicas", promovendo a "justiça social, a igualdade de oportunidades e as necessárias correções das desigualdades na distribuição da riqueza e do rendimento"26.

Ademais, há uma outra atribuição sui generis do tributo, que não objetiva unicamente um viés de arrecadação e de distribuição de riquezas para diminuição de desigualdades sociais e regionais, mas, sim, tem o escopo de interferir na economia, conhecida como função extrafiscal do tributo.

Como elucida a mesma autora lusitana Suzana Tavares da Silva (2015, p. 27) o tributo exerce grande influência no comportamento dos respectivos sujeitos passivos. Segue citando interessante exemplo:

Quando o legislador cria um imposto ou aumenta a respectiva taxa, tornando mais oneroso determinado facto tributário, deve tomar em consideração os possíveis efeitos económicos que esta decisão vai ocasionar: se um bilhete de futebol antes sujeito ao IVA de $6 \%$ passa a ser tributado a uma taxa de $23 \%$, o legislador não pode ignorar que essa modificação pode originar a redução do número de espectadores nos jogos de futebol e com isso interferir no financiamento dos clubes e dos agentes desportivos (SILVA, 2015, p. 27-28).

Assim, a tributação toma um contorno de criação de tributos não para, de forma simplória, arrecadar tributos, mas, sim, para estimular ou não comportamentos ou setores econômicos.

Segundo Casalta Nabais:

A extrafiscalidade traduz-se no conjunto de normas que, embora formalmente integrem o direito fiscal, tem por finalidade principal ou dominante a consecução de determinados resultados econômicos ou sociais através da utilização do instrumento fiscal e não a obtenção de receitas para fazer frente face às despesas públicas (NABAIS, 2009, p. 629).

Prossegue o autor português:

De outro lado, é de salientar que a extrafiscalidade se expande por dois grandes domínios, cada um deles traduzindo uma técnica de intervenção ou de conformação social por via fiscal: a dos impostos extrafiscais, orientados para a dissuação ou evitação de determinados comportamentos (em que são de integrar os chamados agravamentos extrafiscais de impostos fiscais), e a dos benefícios fiscais dirigidos ao fomento, incentivo ou estímulo de determinados comportamentos (NABAIS, 2009, p. 630).

26 PORTUGAL. DECRETO-LEI № 398, DE 17 DE DEZEMBRO DE 1998. Disponível em: <https://www.pwc.pt/pt/pwcinforfisco/ codigos/lgt/dl-398-98.html\#art5>. Acesso em 24 jun. 2019. 
Assim, resumindo, a fiscalidade nada mais é do que a maneira adotada pelo Estado para arrecadar tributos, enquanto que a extrafiscalidade é a utilização do tributo para obter os efeitos econômicos e sociais desejados (TORRES, 1999, p. 135).

Os incentivos fiscais são destinados a promover o equilíbrio socioeconômico entre as diferentes regiões do País (artigo 151, I, cumulado com o artigo 43, § 2º-ambos da Constituição Federal de 1988). Os benefícios fiscais, criados com base na extrafiscalidade, devem ser utilizados em caráter residual e com parcimônia, pelo legislador, para não quebrar o equilíbrio natural do mercado, criando benefícios odiosos e ferindo de morte o basilar princípio da isonomia.

Paulo Caliendo orienta que:

[...] o uso de isenções e benefícios fiscais é uma medida excepcional em nosso sistema, fundado na fiscalidade. A sua utilização deve ser complementar e coerente com o sistema geral, não podendo servir para criar novas iniquidades, complexidade desnecessária no sistema ou desorganizar o sistema econômico por isenções distorcivas do mercado. A proteção do mercado é uma questão de ordem pública em nosso sistema ${ }^{27}$.

A concessão de benefícios, no entanto, não pode ficar a mercê de interesses políticos e econômicos, mormente os defendidos por lobbies, no mais das vezes obscuros, como refere Buffon (2009, p. 224).

Assim, de suma importância, destacar que aplicando com correção essa função do tributo, indubitavelmente, alcançar-se-á, com louvor, o tão almejado desenvolvimento nacional, fomentando com maestria as mais variadas regiões do país, criando um ambiente desenvolvimentista. É papel forte do Estado assim proceder.

Ademais, uma aplicação tributária com um viés mais focado na seletividade, na essencialidade e na progressividade podem ser um meio importante de alavancagem do desenvolvimento, melhorando sensivelmente as liberdades individuais e coletivas em um país com dimensões abissais.

Assim, ashipóteses deseletividadeexistentes noImposto sobreProdutos Industrializados (IPI) e no Imposto sobre Operações relativas à Circulação de Mercadorias e sobre Prestações de Serviços de transporte interestadual e intermunicipal e de comunicação, ainda que as operações e as prestações se iniciem no exterior (ICMS), e com relação à progressividade, temse o Imposto sobre Propriedade Predial e Territorial Urbana (IPTU), Imposto Territorial Rural (ITR) e Imposto sobre a Renda e Proventos de Qualquer Natureza (IR). Entretanto, em que pese o esforço tributário ocorrido, não é autossuficiente, haja vista que, na gama de tributos existentes, vê-se que essa realidade não é regra no sistema constitucional tributário.

Nesta senda, no bojo do que se expôs neste e nos tópicos alhures, medidas de cunho estatal tem o condão de fomentar políticas extrafiscais e, assim, minorar as falhas na liberdade e no desenvolvimento. Vide, como exemplo, a Zona Franca de Manaus, que foi criada em idos de 1957, por meio da Lei no 3.173, de 6 de junho de $1957^{28}$. A lei foi complementada pelo Decretolei no $\mathbf{2 8 8}$, de 28 de fevereiro de $1967^{29}$, aduzindo que a Zona Franca de Manaus é "uma área de livre comércio de importação e exportação e de incentivos fiscais especiais, estabelecida com a finalidade de criar no interior da Amazônia um centro industrial, comercial e agropecuário",

27 CALIENDO, Paulo. Tributação e ordem econômica: os tributos podem ser utilizados como instrumentos de indução econômica? Disponível em: <http://revistaeletronicardfd.unibrasil.com.br/index.php/rdfd/article/view/685/471>. Acesso em: 21 jun. 2019, p. 197.

28 BRASIL. LEI № 3.173, DE o6 DE JUNHO DE 1957. Cria uma zona franca na cidade de Manaus, capital do Estado do Amazonas, e dá outras providências. Disponível em: <http://www.planalto.gov.br/ccivil_03/LEIS/1950-1969/L3173.htmimpressao.htm>. Acesso em: 24 jun. 2019.

29 BRASIL. DECRETO-LEI № 288, DE 28 DE FEVEREIRO DE 1967. Altera as disposições da Lei número 3.173 de 6 de junho de 1957 e regula a Zona Franca de Manaus. Disponível em: <http://www.planalto.gov.br/ccivil_03/decreto-lei/deloz88.htm>. Acesso em: 24 jun. 2019. 
ou seja, fomentando aquela região distante dos grandes centros. Esse mesmo Decreto-lei aduziu que o prazo das isenções previstas para a Zona Franca seria de 30 anos, podendo ser prorrogada.

O Ato das Disposições Constitucionais Transitórias (ADCT) enunciou que fica "mantida a Zona Franca de Manaus, com suas características de área livre de comércio, de exportação e importação, e de incentivos fiscais, pelo prazo de vinte e cinco anos, a partir da promulgação da Constituição".

Em 2003, a Emenda Constitucional no $4^{2^{30}}$, alterou o ADCT e incluiu prazo de dez anos para a Zona Franca de Manaus. A Emenda Constitucional no 83, de o5 de agosto de 2014 ${ }^{31}$, incluiu um novel artigo no ADCT, para definir que "Art. 92-A. São acrescidos 50 (cinquenta) anos ao prazo fixado pelo art. 92 deste Ato das Disposições Constitucionais Transitórias", ou seja, ampliando para 2073.

De bom tom a citação da Exposição de Motivos da Proposta de Emenda à Constituição no 103/2011, que procedeu a ampliação do prazo da Zona Franca por mais 50 anos, demonstra a importância de ferramentas como essa para desenvolvimento de uma região menos favorecida do país, que assim dispõe:

O estágio atual do Polo Industrial de Manaus - PIM pode ser mensurado por diversos indicadores econômicos e sociais relevantes, como a geração de mais de 118 mil empregos diretos e quase 500 mil indiretos, os mais de 35 bilhões de dólares faturados em 2010 e os mais de 10 bilhões de dólares em investimentos existentes. Ressalte-se que essa dinâmica econômica ocorre dentro de um contexto de sustentabilidade ambiental, na medida em que contribui para a preservação de $98 \%$ da cobertura florestal do Estado do Amazonas e a amenização dos efeitos danosos causados pelas mudanças climáticas ao redor do planeta, corroborando e fortalecendo o modelo ZFM adotado pelo Brasil na região amazônica ${ }^{32}$.

A Zona Franca de Manaus é apenas um exemplo claro de implementação de políticas tributárias com o fito de desenvolver e gerar melhoria nas liberdades de uma região com menor impacto, gerando o objetivo do desenvolvimento nacional e mais equânime de todas as regiões do país.

Existem outros exemplos bastante importantes ao redor de todo o país, com esse fito de melhoramentos no desenvolvimento. A Zona Franca de Manaus talvez seja o maior exemplo e com maiores repercussões.

Nesse cotejo de ideias, a Zona Franca de Manaus, o Programa Rota 2030, entre outros são ações governamentais muito maiores do que o fito único de arrecadação tributária.

Outra medida que pode ser citada é a modernização da agricultura familiar como parte de uma estratégia para estimular o desenvolvimento rural, por meio de incentivos fiscais, para que essas famílias possam de alguma forma produzir maiores riquezas para o país. O Brasil tem no seu DNA esse viés rural, porém, com os vários problemas econômicos-sociais, as famílias realizaram o êxodo rural, gerando ou agravando os problemas das cidades, tais como, pobreza, ocupações irregulares, migração de estados do Norte e Nordeste para os estados sulistas.

Outro benefício acima indicado, que bebe nas fontes da Constituição Federal, é o incentivo para micro e pequenas empresas nacionais, com fulcro nos artigos 170, IX e 179. O 3o BRASIL. EMENDA CONSTITUCIONAL № 42, DE 19 DE DEZEMBRO DE 2003. Altera o Sistema Tributário Nacional e dá outras providências. Disponível em: <http://www.planalto.gov.br/ccivil_o3/constituicao/emendas/emc/emc42.htm>. Acesso em: 24 jun. 2019.

31 BRASIL. EMENDA CONSTITUCIONAL № 83, DE 5 DE AGOSTO DE 2014. Acrescenta o art. 92-A ao Ato das Disposições Constitucionais Transitórias - ADCT. Disponível em: <http://www.planalto.gov.br/ccivil_o3/constituicao/Emendas/Emc/emc83. htm>. Acesso em: 24 jun. 2019.

32 BRASIL. PROPOSTA DE EMENDA À CONSTITUIÇÃO № 103, DE 26 DE OUTUBRO DE 2011. Acresce o art. 92-A ao Ato das Disposições Constitucionais Transitórias. Disponível em: <https://www.camara.leg.br/proposicoesWeb/prop_ mostrarintegra?codteor=933553\&filename=PEC+103/2011>. Acesso em: 24 jun. 2019. 
regime do Simples Nacional, com base na Lei no 123/2006 e suas alterações, como já mencionado no capítulo acima, criaram um sistema de incentivos para as empresas de porte menor no Brasil, universalizando a atividade empresarial e o pequeno empreendedor. Juntamente a esse sistema, foi criado o Microempreendedor Individual (MEI), que coloca os autônomos que eram pessoas normalmente informais e à margem do sistema previdenciário, dentro de um sistema de pagamento de contribuição previdenciária e dos impostos municipal e estadual, com baixa contribuição e uma gama de direitos.

Não se pode deixar de citar o incentivo fiscal às cooperativas, haja vista que o sistema vem crescendo, inclusive atingindo searas antes não navegadas, tal como cooperativas de consumo e de crédito, em concorrência aos mercados e bancos tradicionais. $\mathrm{O}$ sistema cooperativo elenca benefícios com o fito de melhorar a qualidade de vida dos cooperados e aumento na competitividade.

Conjugando tudo o que foi dito, pode-se analisar que o desenvolvimento não é apenas um mero crescimento econômico. Obviamente, que o crescimento econômico também é salutar, mas o ideal é conciliar crescimento com desenvolvimento. Assim, mister que haja a distribuição dessa riqueza em favor do bem-estar social, ocasionando mudanças significativas nos índices de desenvolvimento humano, com a efetivação da dignidade da pessoa humana, bem como atingir um fortalecimento das liberdades.

Realizando esse liame, o precitado IRBES será radicalmente modificado no Brasil, para melhor, fazendo com que se tenha uma similitude entre a carga tributária e o Índice de Desenvolvimento Humano (IDH), melhorando, sem dúvida, o papel do tributo na sua função extrafiscal, na diminuição das desigualdades sociais, regionais, culturais e na melhoria da liberdade econômica e individual dos cidadãos.

Assim, é hialino que a tributação é uma excelente ferramenta para a realização do desenvolvimento e melhoria na liberdade, devendo ser cada vez mais utilizado para chegar ao objetivo almejado pela República Federativa do Brasil.

\section{${ }_{5}$ CONCLUSÃO}

Desenvolvimento e liberdade tornou-se um binômio muito importante para os Estados hodiernamente. Isso, pois, o Desenvolvimento é um dos objetivos a ser alcançado pela República Federativa do Brasil. Porém, desenvolver não é simplesmente um crescimento econômico, que é um dado meramente numérico. Busca-se um desenvolvimento mais amplo, com atingimento de reflexos sociais, educacionais, saneamento básico, sustentabilidade ambiental e efetivação da dignidade da pessoa humana, com reflexos diretos no Índice de Desenvolvimento Humano (IDH).

Assim, tem papel de destaque a aproximação entre as liberdades individuais, sociais, econômicas para o atingimento satisfatório do desenvolvimento querido pelo país.

Nesse sentido, diversas medidas de cunho importante tem sido realizadas no Brasil com o mote de implementar políticas públicas de melhoria nos critérios de liberdade dos indivíduos e da nação e, por via reflexa, fomentando o desenvolvimento, criando uma amálgama no sistema que irá melhorar o contexto da vida dos brasileiros.

De sobremaneira o tributo tem um papel de vanguarda para o alcance dessas políticas desenvolvimentista e que fomentem uma melhor absorção das liberdades humanas, haja vista que além de arrecadar tributos, função básica e de suma importância, possui uma outra, de não menor valia, que é a repartição para minorar a pobreza e a função extrafiscal, qual seja, 
interferir na economia para alavancar ou desincentivar consumo de produtos, serviços e condutas da iniciativa privada no cotidiano.

É, por óbvio, função de grande acuidade no sistema tributário, porém, não perdendo de vista que isso não poderá, em condições normais, prejudicar a livre iniciativa do mundo dos negócios, que deve ser sustentado pelas bases da igualdade, sob pena de vilipêndio à Constituição Federal. Eis a festejada regra da neutralidade fiscal, alicerce do sistema econômico.

Por isso, deveras salutar que o Estado use políticas tributárias enigmáticas para fomentar o desenvolvimento, alinhavado às ideias das liberdades, buscando fomentar a economia do país. Típico exemplo dessa construção é a Zona Franca de Manaus que recentemente foi ampliada para mais cinquenta anos, gerando progresso, crescimento e desenvolvimento para uma região brasileira que detinha problemas de ordem social, econômica e, que foram amenizados por essa política pública-fiscal a partir dos anos 1960.

Existem outros exemplos de bom uso de ferramentas tributárias indicadas no texto para melhoria dos critérios de desenvolvimento e liberdade e que devem cada vez mais serem ampliadas, com o fito de implementar as políticas públicas e o aditamento do IDH, fazendo com que a sensação de carga tributária exacerbada saia da mentalidade das pessoas, fazendo com que sintam que pagar tributo gera um bem coletivo e, porque não, individual.

O Î́ndice IRBES indicado alhures coloca o Brasil em posição de alerta, haja vista que os tributos pagos, direta ou indiretamente, não estão atingindo aprimoramento nos índices de desenvolvimento da população, não ampliando educação, ensino, saúde, saneamento etc., gerando uma sensação de que paga-se tributo em excesso sem o devido retorno em serviços públicos.

Os governantes tem o papel fundamental de implementar medidas de controle das contas públicas e melhor uso dos valores arrecadados, aplicando em políticas públicas que representem uma saída do retrocesso e o alcance do tão almejado desenvolvimento com o respeito às liberdades do homem. Nesse contexto, as ferramentas tributárias exercem papel de grande valia para atingir o desenvolvimento.

\section{REFERÊNCIAS}

AMARAL, Gilberto do Amaral; OLENIKE, João Eloi; AMARAL, Letícia Mary Fernandes do. Cálculo do IRBES. Disponível em: <http://ibpt.impostometro.s3.amazonaws.com/ Arquivos/o6\%2BIRBES\%2B2015.pdf>. Acesso em: 10 jun. 2019.

BECKER. Alfredo Augusto. Teoria geral do direito tributário. 2. ed, São Paulo: Saraiva, 1972.

BRASIL. DECRETO-LEI № 288, DE 28 DE FEVEREIRO DE 1967. Altera as disposições da Lei número 3.173 de 6 de junho de 1957 e regula a Zona Franca de Manaus. Disponível em: <http:// www.planalto.gov.br/ccivil_03/decreto-lei/delo288.htm>. Acesso em: 24 jun. 2019.

BRASIL. EMENDA CONSTITUCIONAL № 42, DE 19 DE DEZEMBRO DE 2oo3. Altera o Sistema Tributário Nacional e dá outras providências. Disponível em: <http://www.planalto. gov.br/ccivil_o3/constituicao/emendas/emc/emc42.htm>. Acesso em: 24 jun. 2019. 
BRASIL. EMENDA CONSTITUCIONAL № 83, DE 5 DE AGOSTO DE 2014. Acrescenta o art. 92-A ao Ato das Disposições Constitucionais Transitórias - ADCT. Disponível em: <http:// www.planalto.gov.br/ccivil_03/constituicao/Emendas/Emc/emc83.htm>. Acesso em: 24 jun. 2019 .

BRASIL. LEI № 3.173, DE o6 DE JUNHO DE 1957. Cria uma zona franca na cidade de Manaus, capital do Estado do Amazonas, e dá outras providências. Disponível em: <http://www. planalto.gov.br/ccivil_03/LEIS/1950-1969/L3173.htmimpressao.htm>. Acesso em: 24 jun. 2019.

BRASIL. LEI № 13.755, DE 10 DE DEZEMBRO DE 2018. Estabelece requisitos obrigatórios para a comercialização de veículos no Brasil; institui o Programa Rota 2030 - Mobilidade e Logística; dispõe sobre o regime tributário de autopeças não produzidas; e altera as Leis n 0 9.440, de 14 de março de 1997, 12.546, de 14 de dezembro de 2011, 10.865, de 30 de abril de 2004, 9.826 , de 23 de agosto de $1999,10.637$, de 30 de dezembro de $2002,8.383$, de 30 de dezembro de 1991, e 8.989, de 24 de fevereiro de 1995, e o Decreto-Lei no 288, de 28 de fevereiro de 1967. Disponível em: <http://www.planalto.gov.br/ccivil_03/_ato2015-2018/2018/Lei/L13755.htm>. Acesso em: 21 jun. 2019.

BRASIL. LEI COMPLEMENTAR № 123, DE 14 DE DEZEMBRO DE 20o6. Institui o Estatuto Nacional da Microempresa e da Empresa de Pequeno Porte; altera dispositivos das Leis no 8.212 e 8.213, ambas de 24 de julho de 1991, da Consolidação das Leis do Trabalho - CLT, aprovada pelo Decreto-Lei no 5.452, de 10 de maio de 1943, da Lei no 10.189, de 14 de fevereiro de 2001, da Lei Complementar no 63, de 11 de janeiro de 1990; e revoga as Leis no 9.317, de 5 de dezembro de 1996, e 9.841, de 5 de outubro de 1999. Disponível em: <http://www.planalto.gov.br/ccivil_03/ leis/lcp/lcp128.htm>. Acesso em: 23 jun. 2019.

BRASIL. LEI COMPLEMENTAR № 128, DE 19 DE DEZEMBRO DE 20o8. Altera a Lei Complementar no 123, de 14 de dezembro de 2006, altera as Leis nos 8.212, de 24 de julho de 1991, 8.213, de 24 de julho de 1991, 10.406, de 10 de janeiro de 2002 - Código Civil, 8.029, de 12 de abril de 1990, e dá outras providências. Disponível em: <http://www.planalto.gov.br/ccivil_03/ leis/lcp/lcp128.htm>. Acesso em: 23 jun. 2019.

BRASIL. LEI COMPLEMENTAR № 155, DE 27 DE OUTUBRO DE 2016. Altera a Lei Complementar no 123, de 14 de dezembro de 2006, para reorganizar e simplificar a metodologia de apuração do imposto devido por optantes pelo Simples Nacional; altera as Leis nos 9.613, de 3 de março de 1998, 12.512, de 14 de outubro de 2011, e 7.998, de 11 de janeiro de 1990; e revoga dispositivo da Lei no 8.212, de 24 de julho de 1991. Disponível em: <http://www.planalto.gov. br/ccivil_03/leis/lcp/lcp128.htm>. Acesso em: 23 jun. 2019.

BRASIL. LEI COMPLEMENTAR № 166, DE o8 DE ABRIL DE 2019. Altera a Lei Complementar no ${ }^{10}$, de 10 de janeiro de 2001, e a Lei no $\mathbf{1 2 . 4 1 4}$, de 9 de junho de 2011, para dispor sobre os cadastros positivos de crédito e regular a responsabilidade civil dos operadores. Disponível em: <http://www.planalto.gov.br/ccivil_03/leis/lcp/Lcp166.htm>. Acesso em: 21 jun. 2019. 
BRASIL. MEDIDA PROVISÓRIA № 843, DE 5 DE JULHO DE 2018. Estabelece requisitos obrigatórios para a comercialização de veículos no Brasil, institui o Programa Rota 2030 Mobilidade e Logística e dispõe sobre o regime tributário de autopeças não produzidas. Disponível em: <http://www.planalto.gov.br/ccivil_03/_ato2015-2018/2018/Mpv/mpv843.htm>. Acesso em: 21 jun. 2019.

BRASIL. MEDIDA PROVISÓRIA № 881, DE 30 DE ABRIL DE 2019. Institui a Declaração de Direitos de Liberdade Econômica, estabelece garantias de livre mercado, análise de impacto regulatório, e dá outras providências. Disponível em: <http://www.planalto.gov.br/ccivil_03/_ ato2019-2022/2019/Mpv/mpv881.htm>. Acesso em: 21 jun. 2019.

BRASIL. Ministério da Economia. Medida que facilitará acesso ao crédito foi sancionada nesta segunda-feira (8). Disponível em: <http://www.economia.gov.br/noticias/2019/o4/ medida-que-facilitara-acesso-ao-credito-e-sancionada-nesta-segunda-feira-o8>. Acesso em: 21 jun. 2019.

BRASIL. MINISTÉRIO DA ECONOMIA. Rota 2030 - Mobilidade e Logística. Disponível em: $<$ http://www.mdic.gov.br/index.php/competitividade-industrial/setor-automotivo/rota2030 $>$. Acesso em: 21 jun. 2019.

BRASIL. Portal do Empreendedor. Disponível em: <http://www.portaldoempreendedor.gov. br/estatisticas $>$. Acesso em: 23 jun. 2019.

BRASIL. PROPOSTA DE EMENDA À CONSTITUIÇÃO № $103, \quad$ DE 26 DE OUTUBRO DE 2011. Acresce o art. 92-A ao Ato das Disposições Constitucionais Transitórias. Disponível em: <https://www.camara.leg.br/proposicoesWeb/prop_ mostrarintegra?codteor $=933553 \&$ filename $=P E C+103 / 2011>$. Acesso em: 24 jun. 2019.

BUFFON, Marciano. Tributação e dignidade humana: entre os direitos e deveres fundamentais. Porto Alegre: Livraria do Advogado Editora, 2009.

CALEIRO, João Pedro. 15 países que mais investem em pesquisa (e o Brasil em 36ª). Disponível em: <https://exame.abril.com.br/economia/15-paises-que-mais-investem-empesquisa-e-o-brasil-em-36o/>. Acesso em: 21 jun. 2019.

CALIENDO, Paulo. Tributação e ordem econômica: os tributos podem ser utilizados como instrumentos de indução econômica? Disponível em: <http://revistaeletronicardfd.unibrasil. com.br/index.php/rdfd/article/view/685/471>. Acesso em 21 jun. 2019.

CORREIO BRAZILIENSE. China está entre as 20 economias mais inovadoras; Brasil ocupa $64^{-}$lugar. Disponível em: <https://www.correiobraziliense.com.br/app/noticia/ economia/2018/o7/10/internas_economia,694018/china-esta-entre-as-2o-economias-maisinovadoras-brasil-ocupa-64-lug.shtml>. Acesso em 21 jun. 2019.

DORN, James A. Biografia: Peter Bauer. Disponível em: <http://ordemlivre.org/posts/ biografia-peter-bauer>. Acesso em 21 jun. 2019. 
FURTADO, Celso. Cultura e Desenvolvimento em Épocas de Crise. Rio de Janeiro: Paz e Terra, 1984.

GLOBAL INNOVATION INDEX. Disponível em: <https://www.globalinnovationindex.org/ Home>. Acesso em: 21 jun. 2019.

NABAIS, José Casalta. O dever fundamental de pagar impostos: contributo para a compreensão constitucional do estado fiscal contemporâneo. Coimbra: Almedina, 2009.

NAÇÕES UNIDAS BRASIL. China entra para grupo de 20 economias mais inovadoras do mundo. Disponível em: <https://nacoesunidas.org/china-entra-para-grupo-de-20economias-mais-inovadoras-do-mundo/>. Acesso em: 21 jun. 2019.

PIKETTY, Thomas. O Capital no século XXI. Rio de Janeiro: Intrínseca, 2014.

PORTUGAL. DECRETO-LEI No 398, DE 17 DE DEZEMBRO DE 1998. Disponível em: < https:// www.pwc.pt/pt/pwcinforfisco/codigos/lgt/dl-398-98.html\#art5>. Acesso em 24 jun. 2019.

SACHS, Ignacy. Desenvolvimento includente, sustentável e sustentato. Rio de Janeiro: Garamond, 2008.

SEN, Amartya. Desenvolvimento como liberdade. São Paulo: Companhia das Letras, 2000.

SILVA, Suzana Tavares da. Direito Fiscal: teoria geral. 2. ed. Coimbra: Imprensa da Universidade de Coimbra, 2015.

TORRES, Ricardo Lobo. Tratado de direito constitucional financeiro e tributário. Rio de Janeiro: Renovar, 1999. 